\title{
2027 Accuracy and reproducibility of quantifying myocardial fibrosis in hypertrophic cardiomyopathy using delayed enhancement cardiovascular magnetic resonance thresholding techniques
}

\author{
Harrigan J Caitlin*1, Martin S Maron², Barry J Maron³, Dana C Peters ${ }^{4}$, C \\ Michael Gibson ${ }^{1,5,1}$, Warren J Manning ${ }^{1}$ and Evan Appelbaum ${ }^{1}$
}

Address: ${ }^{1}$ Perfuse Core Laboratory \& Data Coordinating Center, Harvard Medical School, Boston, MA, USA, ${ }^{2}$ Tufts-New England Medical Center, Boston, MA, USA, ${ }^{3}$ Minneapolis Heart Institution Heart Foundation,, Minneapolis, MN, USA, ${ }^{4}$ Beth Israel-Deaconess Hospital, Boston, MA, USA and ${ }^{5}$ Beth Israel-Deaconess Medical Center, Boston, MA, USA

* Corresponding author

from I I th Annual SCMR Scientific Sessions

Los Angeles, CA, USA. I-3 February 2008

Published: 22 October 2008

Journal of Cardiovascular Magnetic Resonance 2008, I0(Suppl I):A296 doi:I0.I I86/I532-429X-I0-SI-A296

This abstract is available from: http://jcmr-online.com/content/I0/SI/A296

(c) 2008 Caitlin et al; licensee BioMed Central Ltd.

\section{Background}

Cardiovascular magnetic resonance (CMR) with delayed enhancement (DE) has become the gold standard for the identification and quantification of myocardial fibrosis in coronary artery disease. In this regard, DE thresholding to 2 standard deviations above normal myocardium is now considered the most robust method for quantifying fibrosis with high accuracy and reproducibility. However, whether this method is the most appropriate for nonischemic cardiomyopathies such as hypertrophic cardiomyopathy remains uncertain. Our goal was to compare the performance of various thresholding techniques to a visual assessment in a large cohort of patients with hypertrophic cardiomyopthy (HCM).

\section{Methods}

DE-CMR imaging was performed 15 minutes after the intravenous administration of $0.2 \mathrm{mmol} / \mathrm{kg}$ of gadolinium-DTPA (Magnevist, Schering; Berlin, Germany) with a breath-hold segmented inversion-recovery sequence $(\mathrm{TI}=$ $240-300 \mathrm{~ms}$ ), in $203 \mathrm{HCM}$ patients (42 \pm 17 years; $71 \%$ male) from two HCM referral centers. Two blinded, independent readers first quantified fibrosis by visual assessment then using thresholds of 2 standard deviations (SD), 3 SD, 4 SD, 6 SD above the mean of normal, remote myocardium, and $2 \mathrm{SD}$ above noise ( $2 \mathrm{SDN}$ ). The quantification was repeated $\geq 4$ weeks apart for reproducibility.

\section{Results}

DE was present in $51 \%$ of subjects, with an interobserver agreement of $93 \%$. For the detection of fibrosis, 6 SD correlated best with visual assessment as compared to 2, 3, 4 $\mathrm{SD}$, or $2 \mathrm{SDN}$. Average visual quantity of fibrosis was $13 \pm$ $20 \mathrm{~g}$ compared with $12 \pm 17 \mathrm{~g}$ at $6 \mathrm{SD}$, and $55 \pm 31 \mathrm{~g}$ at 2 $\mathrm{SD}, 36 \pm 27 \mathrm{~g}$ at $3 \mathrm{SD}, 25 \pm 23 \mathrm{~g}$ at $4 \mathrm{SD}$, and $64 \pm 69 \mathrm{~g}$ at 2 SDN. All thresholds were significantly correlated with visual assessment, with $6 \mathrm{SD}$ having the most robust correlation $(\mathrm{r}=0.913, \mathrm{p}<0.0001)$ vs. $2 \mathrm{SD}, 3 \mathrm{SD}, 4 \mathrm{SD}$, and 2 SDN ( $\mathrm{r}=0.806,0.874,0.905,0.533$, respectively; all $\mathrm{p}$ $<0.001)$. Compared with visual assessment, $6 \mathrm{SD}$ had the lowest intraobserver variability $(0.6 \pm 8 \mathrm{~g}, \mathrm{\kappa}=0.66$; $\mathrm{p}<$ 0.0001 vs. $1.4 \pm 9 \mathrm{~g}, \kappa=0.49 ; \mathrm{p}<0.0001)$ and interobserver variability $(5.4 \pm 18 \mathrm{~g}, \mathrm{\kappa}=0.20 ; \mathrm{p}<0.0001$ vs. -18.4 $\pm 18 \mathrm{~g}$, $\kappa=0.08 ; \mathrm{p}<0.0001)$.

\section{Conclusion}

CMR DE thresholding techniques utilizing 6 SD above the mean of visually normal, remote myocardium appears to be both an accurate and reproducible method for the quantification of myocardial fibrosis in HCM. This methodology should be considered for serial assessment of myocardial fibrosis in longitudinal HCM studies. 